\title{
See in Still Water: A Short Study on Experiencing and Representing Lake
}

\author{
ZHONG Jing-dong \\ Zhejiang Yuexiu University of Foreign Languages, Shaoxing, China
}

\begin{abstract}
This paper attempts to discuss a possible way of seeking a temporary dwelling place for the soul and keeping a sense of "whereness" in an ever changing world. The study first analyzes the conceptions of "whereness" and still point, proposing the water face as the satisfactory means to achieve it on the basis of analyzing Thoreau's Walden, then in a comparative way this paper examines several texts concerning the experiences and representations of physical and spiritual contacts with running water like rivers or still water like lakes, among which the texts concerning the English lakes are given main attentions. The study finds that the preferable mode of experiencing and representing lake denotes the universality and should be adopted more.
\end{abstract}

Keywords: still point, lake, running water, Thoreau, William Gilpin, Wordsworth

\section{Introduction}

"I shall never forget the first view of Crummock Water, still and deserted... the sky was clear and yet the chill of early morning gave freshness to the air", and in "the stillness of an early spring day with few people and even fewer cars on the road, it is possible to hear bird song and the bleat of sheep; near the lakeside there is the gentle lap of the water on a deserted shoreline" (Hammett, 2012, pp. 2-4, emphasis added), in his impressive 2012 travel book Nigel Hammett thus recalls his first tour to the English lakes, which struck him with the precious stillness. Feeling "the silence of that first view and from that moment", he has "enjoyed so much peace of mind and serenity of spirit in this wonderful landscape” (Hammett, 2012, p. 2, emphasis added). This proves, as Stephen J. Spector (1977) points out, that one "needs only a lucky combination of a moment of silence and an externally induced 'gentle shock' for his mind to perfectly mirror the external world", and consequently the "union of the mind and the world" could occur "during such privileged moments" (Spector, 1977, p. 95, emphasis added). However, one thing is for certain: Hammett is far from being the first person who "recovers a kind of spiritual integrity and wisdom by immersion" (Andrews, 1999, p. 31) in a still waterscape. Through examining several texts concerning such experiences and representations of physical and spiritual contacts with running water like rivers or still water like lakes, this paper attempts to discuss a possible way of seeking a temporary dwelling place for the soul and keeping a sense of "whereness” (O’Donohue, 2010, p. 143) in a forever changing world.

ZHONG Jing-dong, Associate Professor, English Faculty, Zhejiang Yuexiu University of Foreign Languages, Shaoxing, China. 


\section{Still Point and Water Surface}

In contemporary Irish philosopher John O’Donohue’s eyes, a sense of “whereness” is “crucial to human identity", for without it "neither language, person nor thought could commence. All the fundamental imagery of the world would be impossible" and the "human journey, the search for meaning, would be inconceivable" (2010, p. 143). But what is a sense of whereness? To put it simply, it means that someone knows where he is and without confusion he can locate his state of being in a particular place. To obtain and maintain such a sense, he has "a constant need for the physical, sensuous, elemental interaction with the actual landscape", for "humans emerge from landscape” (2010, p. xiii). O’Donohue states further that "landscape can bring you deeper into the mystery of 'why you are here' if you can enter the realm of imagination" (2010, pp. xiv-xv), which "attends to the flow of life" and "works to discover the forms of perception and possibility that we need for our journey" (2010, p. 46). The entrance to this realm and such an ideal interaction with landscape needs patience and stillness in mind, for "landscape and its inhabitants exist mainly in the mode of stillness and silence" and "Its stillness is also the absence of movement” (2010, p. 149, emphasis added), but as O'Donohue points out, humans "are always going somewhere else" in spite of the existence in the landscape, and such "inability to sit still” leads to many problems, one of which is that humans "have hijacked all the mystical qualities for the mind" (2010, p. xiv). Perhaps the prompt solution now is to go back to live "in the midst of Nature and has his senses still” (Hodder, 2001, p. 75) so as to find a still point for oneself.

In the comparative study of T. S. Eliot's Four Quartets and Henry David Thoreau's Walden, Deborah Leiter (2007) observes that both the works consider the life as "a voyage to a spiritual vantage point from which the world could be seen more clearly", and as Eliot's lines go, "We must be still and still moving/Into another intensity/for a further union, a deeper communion", so such a vantage point "required stillness, yet not static" (2007, p. 6, emphasis added). When discussing the relation of these "vantage point" to the unaware world outside of them, Eliot most often uses the image of "the still point of the turning world", concerning "the center of the earth with the world rotating around it", or "perhaps the sun, which is still itself, in a way, but always rotating the things around it" (Leiter, 2007, pp. 7, 61, emphasis added). In O’Donohue's words, "the still point" turns out to be "the stars", "with our gaze of longing fixed on" which "we have stopped off on this earth for a short spell of belonging” during the time when "we journey from the womb of the sea” (2010, p. ix).

As for Thoreau, Leiter points out that his spiritual journey means "one advances confidently in the direction of his dreams" (2007, p. 6), during which it is "by a mathematical point only that we are wise, as the sailor or the fugitive slave keeps the polestar in his eyes" (2007, p. 58). So, as Leiter argues, Thoreau also associates "the still point" in location of "sky, particularly in the celestial bodies (sun, moon, and stars)" and of “the center, or at least the 'roots' or 'bedrock' of the earth” (2007, p. 7), but more significantly, he adds another “in natural settings where one can focus well, particularly at Walden Pond” (2007, p. 7, emphasis added). In fact, Thoreau's description in Walden emphasizes the trope of the movement surrounding the stillness, which

extends to his portrait of the remarkable power of the pond's surface to record all the life and energy around it, its even, smooth plane a medium that can disclose the smallest presence and the finest movements above and below it. (Leither, 2007, p. 61, emphasis added)

Leiter then discusses such recording or finding: "the seemingly conflicting up-down, forward-backward, and 
circling/cycling movement", "seem temporarily harmonized in some ways, but suspended, in some ways, at the point itself, as they are when Thoreau sees the stillness of the surface of Walden Pond” (2007, p. 62). At such a still point there is "Neither movement from nor towards,/Neither ascent nor decline", thus resulting in a "release from action... release from the inner/and the outer compulsion" (Leither, 2007, p. 62). So "a person having reached there can see the true pattern", and "see the world and its patterns, its interconnections, clearly", perhaps "in the same way that Thoreau could see the pattern of the stars in the stream or the pattern of the activity around the surface of Walden Pond” (Leiter, 2007, p. 62, emphasis added).

The discussion above proves that the reflecting and blending properties of the water surface turns it to be a most suitable still point to focus one's sights and consciousness and thus might serve effectively as "an in-between element" that "combines many of the characteritics of the other elements" such as air and stone (O’Donohue, 2010, p. 43). Besides, the water has "a capacity for physical metamorphoses into ripples, wave, storm, and evaporation, and in winter, turning into ice. These modes of being also symbolize the way the human imagination transforms, reflects, and reconstitutes itself” (Neset, 2009, p. 102). In short, through creating a still space and guiding one into "the realm of imagination", the water can help to search for one's identity and place in the world and experience spiritual freedom again (Potocka, 2013, p. 102). The next section will discuss further about the choice of the ideal types of water, and, if possible, their sound combinations with other landscape elements.

\section{See in Running Water}

As one of the major theoreticians who advocated picturesque landscape and picturesque travel, William Gilpin (2014) once classified the sceneries of the water into river scenery, lake scenery, and sea-coast view, considering that the last type on the whole inferior - too spacious to focus well and frequently present the terrors of shipwreck to the exclusion of real tranquility. What he imagined as an ideal landscape was a "miniature utopia” (Smethurst, 2012, p. 147)—for him, both grand rivers and big lakes such as American Great lakes were beyond pleasure, let alone "wanton seas" in the words of Arne Neset (2009), who shows preference for the last two types of water, labeling lakes and ponds as "sweet water" of "holy water" and associating rivers with Eden and Acadia. However, a small lake or a pond is a better candidate for a still point than a river, for the latter belongs to running water. As a discourse in Confucius's words proposed by ancient Chinese philosopher Chuang Ztu (around 369-286 BC) goes: "When standing still, the water is in the most perfect state of repose. Let that be your model. It remains quietly within, and is not agitated without” (Lin, 1942, p. 655). To follow such a model, of course a man shouldn't "seek to see himself in running water, but in still water. For only what is itself still can instill stillness into others" (Lin, 1942, p. 652). Next, two texts of seeing running water will be examined concerning the necessity of seeing a still one.

According to James A. Papa's 2000 paper, in Pilgrim at Tinker Creek, Annie Dillard records her daily walking along a creek which serves as "both inspiration and stage for observation and revelation" (2000, p. 71). As "a fluid, dynamic entity without fixed boundaries", the creek "is continually rushing by her; even the stiller sections are always moving, however slowly" (2000, p. 73), and thus stillness both outside and in the mind is nothing but an illusion, for as the author herself observes: "Scenes drift across the screen [of the mind] from nowhere. I can never discover the connection between any one scene and what I am more consciously 
thinking...the scene is always just slipping out of sight” (2000, p. 73). Operating in the same manner, neither Dillard's consciousness and the creek can fix itself, "even for a moment, among the swirling chaos of the cosmos” (2000, p. 73). "The world and the self are nothing but flux” (2000, p. 78) in Dillard's senses, and she cannot enter into the state of stillness due to the choice of a creek to stay with, which, "though fixed in the landscape like the pond, is itself in perpetual motion, never to be pinned down” (2000, p. 79).

In the case of Thoreau's boating along a river-a more typical body of running water, from a perspective that "enhances observation simply because of the clear, unobstructed line of sight to shore", a man "is distinguished in his role as observer" while floating on an element different from the land (Peck, 1990, p. 23). As H. Daniel Peck points out, since "the view from a boat on a river is necessarily fleeting and dependent upon the speed and direction of the current as well as the wind", it would lead to "the absence of a fixed point of view" (1990, p. 23). When the boat, with the man in it, is always moving, what the man observes, including the reflection on the water surface and the real ones, would change constantly. Consequently, the man's consciousness become, in Spector's words, “complex but not fragmented, multifaceted but not discontinuous” (1990, p. 96).

The brief discussion above reveals that seeing in running water like a creek or a river, no matter in the way of walking or boating, is not so helpful to engage one in a state of dwelling. Instead, a more suitable candidate would be a body of still water like a lake, which is often associated with mirror imagery.

\section{See in Lake: William Gilpin}

"Picturesque formulas for mirror imagery, where the inverted reflection on the water's surface is seen as a painting, originated in eighteenth-century travel literature” (Spector, 1977, p. 86), which are especially concerned with the description of the English Lakes. As early as 1750s, in a letter which was published in 1767, Dr. John Brown described Derwent Water as "a perfect mirror; and the whole landscape in all its beauty, islands, fields, woods, rocks, and mountains, are seen inverted and floating on its surface”, while in the journal letter for 3 October 1769 Thomas Gray repeated Brown's praise of the same lake: "beneath you, \& stretching far away to the right, the shining purity of the Lake, just ruffled by the breeze enough to shew it is alive, reflecting rocks,woods, fields, \& inverted tops of mountains" (Spector, 1977, p. 88). Both descriptions exemplify the Picturesque at its most obvious: the small and round lake itself is a picture made by Nature, whose frame and subject are the lake bank and the landscape which the mirror-water paints respectively.

Ever since then, there were more such lakescape writings, all of which to some degree denote "the inevitable association of reflecting water with reflective calm", and "based upon the analogy of the reflecting water and the reflective mind”, “a harmonious relationship between the mind and the world” (Spector, 1977, pp. 90, 85). William Gilpin is a representative of such an connoisseur of natural beauty, in whose eyes a still lake is perfect, particularly, "when the sky is splendid, and at the same time calm, the water (being then a perfect mirror,) will glow all over with correspondent tints" (2013, p. 99). See the descriptions as follows:

If an artificial mirror, a few inches long, placed opposite to a door, or a window, occasions often very pleasing reflections; how noble must be the appearance, when an area of many leagues in circumserence, is formed into one vast mirror; and this mirror surrounded by a combination of great, and beautiful objects? The majestic repose of so grand, so solemn, and splendid a scene raises in the mind a sort of enthusiastic calm, which spreads a mild complacence over the breast - a tranquil pause of mental operation... Soothing each gust of passion into peace; All but the swellings of the soften'd heart; That waken, not disturb, the tranquil mind. (2013, p. 124, emphasis added) 
This description vividly reveals the interfacing process of the lake scene and the mind and demonstrates the very words of Chuang Ztu's wisdom as quoted before, "only what is itself still can instill stillness into others". Due to the great stillness of this body of water, the scene here is "so grand, so solemn, and splendid" and obtains a sense of "majestic repose", which evokes an "enthusiastic calm" in the mind. This proves unquestionably the psychological function the still lake can fulfill. And "When the mind has a little recovered it's tone, from the general impression of such a scene", and therefore arrives at a satisfactory state, "it feels a new pleasure in examining more minutely the several picturesque ingredients, which produce it", including "the stillness, and purity of the air", "the polish of the lake”, and, “above all, the reflections of displayed upon it's bosom”, when spreading into "a liquid plain”, it "stands unmoved/Pure as the expense of heaven” (Gilpin, 2013, p. 125).

Here, it seems unfair to simply consider Gilpin as a Picturesque traveller, an outsider, in whose eyes "ground, wood, rocks and buildings were 'ornaments' of aesthetically arranged construction” (Bate, 2000, p. 147). To some degree, Gilpin experiences no less than William Wordsworth does, though the latter takes much pride in being a dweller, who "feels with nature" and whose "metaphysic of 'presence' unites air, water and mind" (Bate, 2000, pp. 150, 147).

\section{See in Lake: William Wordsworth}

As a text discussed at the initial part of this paper, Hammett's recall of lake touring is extracted from his book "dedicated to all who love the poetry of William Wordsworth and enjoy the serenity of the Lake District landscapes" according to the author's acknowledgement. Here, an implication that the serene landscape serves as a still point in Wordswords's life at the lakes is not hard to detect. Actually, this relationship can be traced in the journals of Wordsworth's sister, Dorothy. For instance, Dorothy’s journal entry for December 26 in 1801 records how she (and William) was impressed by the stillness of the water and its reflections when passing Grasmere: "It was very pleasant-Grasmere Lake a beautiful image of stillness, clear as glass, reflecting all things, the wind was up, and the waters sounding... how quiet they were!” (Woof, 2002, p. 53, emphasis added). As for Wordsworth, the view of Grasmere from Red Bank (See Figure 1) delighted him at the first sight, which led to the poet's choice of dwelling in this lakeland.

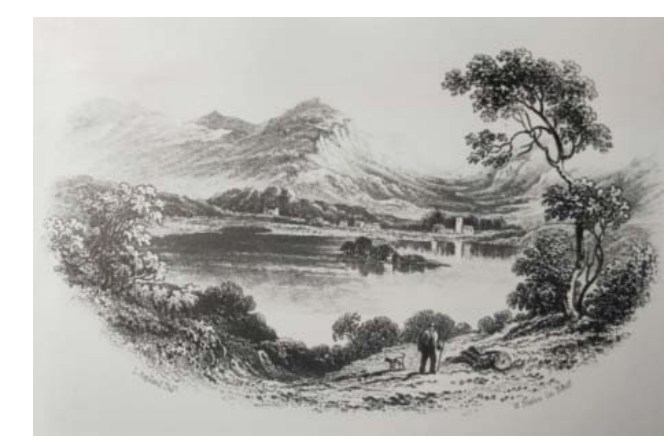

Figure 1. Grasmere from Red Bank by L. Aspland ${ }^{1}$.

In his "great poem of dwelling” (Hess, 2012 , pp. 188, 212)—Home at Grasmere, Wordsworth describes “a perfect union of reflection and reality” based on his experiences of seeing the still lake and its surrounding

\footnotetext{
${ }^{1}$ More pictures concerning the English Lake District, see Peter Blacknell's The Illustrated Wordsworth's Guide to the Lakes (1984). Exeter: Webb \& Bower Ltd.
} 
landscapes. In this text of reflections, the poet first requests us to throw the eye sights upward to "all the distant grove" which "rises to to the summit of the steep" and "Shows like a mountain built of silver light", and then guides us to

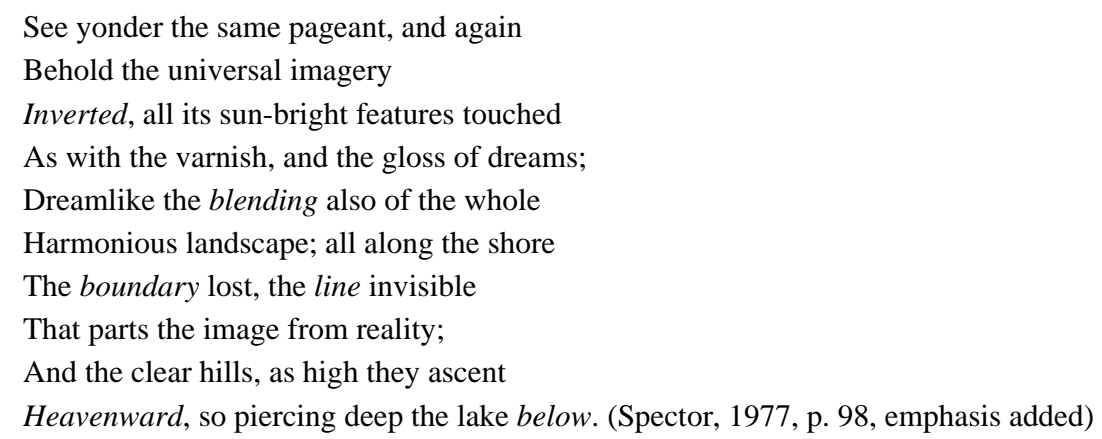

The "distant grove”, which might symbolize the target of one's seemingly endless spiritual or materialistic pursuits, rises too high to reach and turns into an illusion in "silver light". Its temptation and the possible frustration as the result of the pursuits in vain are counterbalanced by the bright inverted "universal imagery" owing to the still lake, for this water

is contemplated with that placid and quiet feeling which belongs peculiarly to the lake-as a body of still water under the influence of no current; reflecting therefore the clouds, the light, and all the imagery of the sky and surrounding hills. (De Selincour, 1977, p. 32)

And, if as Stephen J. Spector interprets, “The key phrase here is 'The boundary lost,' indicating Wordsworth has found his home" (1977, p. 98), this sense of homecoming or dwelling is gained by seeing the still lake, by "forming in his mind a centre or conspicuous point to which objects, otherwise disconnected or insubordinated, may be referred” (De Selincourt, 1977, p. 41).

\section{Conclusion}

The discussions of this paper concentrate on the texts concerning lakescapes like the Walden pond and the English Lake District, which are renowned. For instance, the latter has been added to UNESCO’s World Heritage List as a distinctive cultural landscape being "outstanding in its harmonious beauty, quality, integrity and on-going utility and its demonstration of human interaction with the environment”" ${ }^{2}$. Lakes contributes a lot to forming such distinctive landscape features, making this site obtain Outstanding Universal Value at a globe level. In this sense, it is not hard to understand that the preferable mode of experiencing and representing lake denotes the universality and can be shared by both the West and the Oriental. In an ever changing world, to seek a temporary dwelling place and keep a sense of "whereness", one might turn to see the still water like small lakes from time to time, for only "what is itself still can instill stillness into others” (Lin, 1942, p. 655).

\section{References}

Andrews, M. (1999). Landscape and western art. Oxford \& New York: Oxford University Press.

Bate, J. (2000). The song of the earth. London: Picador.

${ }^{2}$ Detailed descriptions of this lakeland's Outstanding Universal Value, see http://whc.unesco.org/en/list/422. 
De Selincourt, E. (Ed.). ([1906] 1977). Wordsworth's guide to the lakes. Oxford \& New York: Oxford University Press.

Gilpin, W. ([1786] 2013). Observations, relative chiefly to picturesque beauty, made in the year 1772, on several parts of England; particularly the mountains, and lakes of Cumberland, and Westmoreland. Cambridge: Cambridge University Press.

Gilpin, W. ([1804] 2014). Observations on the coasts of Hampshire, Sussex, and Kent, relative chiefly to picturesque beauty, relative to picturesque beauty, made in the summer of the year 1774. Cambridge: Cambridge University Press.

Hammett, N. (2012). Place, nature and spirit: A lake district experience. Lulu. com.

Hess, S. (2012). Wordsworth and the ecology of authorship: The roots of environmentalism in nineteenth-century culture. Charlottesville \& London: University of Virginia.

Hodder, A. D. (2001). Thoreau's ecstatic witness. New Haven \& London: Yale University Press.

Leiter, D. (2007). Toward the still point: T. S. Eliot's Four Quatets and Thoreau's Walden. Saskatoon: University of Saskatchewan. Lin, Y. T. (Ed.). (1942). The wisdom of India and China. New York: Random House.

Neset, A. (2009). Arcadian waters and wanton seas: The iconology of waterscapes in nineteenth-century transatlantic culture. New York: Peter Lang Publishing, Inc.

O’Donohue, J. (2010). The four elements: Reflections on nature. London: Transworld Ireland.

Papa, J. A. (2000). Water-signs: Place and metaphor in Dillard and Thoreau. In R. J. Schneider (Ed.), Thoreau's sense of place: Essays in American environmental writing (pp. 70-79). Iowa City: University of Iowa Press.

Peck, H. D. (1990). Thoreau's morning work: Memory and perception in a week on the Concord and Merrimack Rivers, the Journal, and Walden. New Haven \& London: Yale University Press.

Potocka, I. (2013). The lakescape in the eyes of a tourist. Quaestiones Geographicae, 32(3), 85-97.

Smethurst, P. (2012). Travel writing and the natural world, 1768-1840. New York: Palgrave Macmillan.

Spector, S. J. (1977). Wordsworth's mirror imagery and the picturesque tradition. English Literature History, 44(1), 85-107.

Woof, P. (Ed.). (2002). Dorothy Wordsworth: The Grasmere and Alfoxden journals. Oxford \& New York: Oxford University Press. 